which a dip or rise of the curve would have is a matter for serious argument too long to go into here.

Objections to the application of the theory are less serious but still formidable ; it seems to throw the Riss glaciation too far back, also the Acheulean culture, and brings the Chellean and previous cultures too late: in narrow valleys in the district under review the hypothesis of terrace formation may seem satisfactory, but in wider valleys a dwindling river could not be held able to choke its valley throughout its length with gravel up to, say, $55 \mathrm{~m}$.; also it leaves unanswered the question of valleys with similar terraces away from all ice, e.g. the Nile.

R. G. Lewis.

2nd August, 1935.

\title{
The Centenary of the Geological Survey of Great Britain.
}

GOR many years it was notorious that the home of the Geological I Survey and Museum in Jermyn Street and Piccadilly was quite inadequate for its purpose, and the climax was reached when a bomb dropped at a venture from a Zeppelin gave the old building a bad shake, rendering it positively unsafe. After the usual necessary (or unnecessary) official delays, plans were drawn up, and actually carried out, for a new building on a generous scale in South Kensington. When this building was almost ready for occupation, it was commandeered by the Government for the Imperial Economic Conference, and thus, by what must be regarded as a happy coincidence, the formal opening was deferred till 1935, which happened to be the centenary of the establishment of the Geological Survey.

The new building was formally opened by the Duke of York on Wednesday, 3rd July, and this was followed by a formal celebration of the Centenary. The President and Council of the Geological Society of London also held a reception at Burlington House on the evening of 3rd July in honour of the occasion.

It is officially announced that Sir John Flett, LL.D., F.R.S., is retiring from the Directorship of the Geological Survey in the autumn, and that he is to be succeeded by Dr. Bernard Smith, F.R.S. We should like to express our deep regret at the first of these announcements, and our sincere congratulations to Dr. Smith on the second. 